\title{
The windmills of our minds: a workshop on culture clash in CSCW
}

\author{
G. J. Hofstede \\ Wageningen Agricultural University \\ Department of Computer Science \\ Dreijenplein 2, $6703 \mathrm{HB}$ Wageningen, The Netherlands \\ tel: $+31(0) 317484630$, fax: +31(0)317483158 \\ e-mail: gertjan_hofstede@users@info.wau.nl
}

\begin{abstract}
This paper introduces a workshop in which teams from a number of "synthetic cultures" have to cooperate in order to design a communication architecture for a multinational company. The communication needed is about the sales and maintenance of windmills manufactured by the company. The synthetic cultures are ideal types of the extreme scale values of five well-established, empirically found dimensions of national culture. Four of them are already being used in workshops for intercultural learning. The case study on windmills is fictive. The workshop is set up with a view to obtain confrontations between the synthetic cultures.

The workshop's aim is twofold. At a methodological level, it is intended as a tool for laboratory research into multi-cultural issues in the introduction of Computer-Supported Cooperative Work technologies. As such the present proposal is only a first attempt, which will no doubt be improved with experience. For the participants, the aim is to convey an experience of culture shock which will make them more aware of the pervasive effects of differences in culture on cooperative design processes, and hence of their importance as an item on the research agenda for the International Office of the Future.

The workshop has been held three times at the time of writing, and has proven to live up to its aims.
\end{abstract}

Keywords

$\mathrm{CSCW}$, communication architecture, national culture, gaming, training, research methodology. 


\title{
1 INTRODUCTION
}

\author{
"Different-time / different-place / different-culture workgroups will become the norm." \\ Pieter W.G. Bots et al. (eds), 1995: The International Office of the future: A \\ Problem Analysis. Delft: Technical Univ., Dept. of Systems Engineering, p. v. \\ "There are barriers to communication that are rooted in culture, and these barriers may keep \\ rational, well-intentioned people from communicating accurately with one another." \\ Paul B. Pedersen and Allen Ivey (1993): Culture-centered Counseling and \\ Interviewing Skills. Westport: Praeger. p. 13-14.
}

As the global village becomes smaller, neighbours from different cultures cooperate with each other more and more. Information technology makes it possible for colleagues in different parts of the world to communicate in a variety of ways at any time. Competition and globalization make such communication necessary.

Recently, Computer Supported Cooperative Work (CSCW) has become a keyword for a collection of information technologies to enable communication across time and space. CSCW techniques include, for instance, electronic mail and electronic meetings.

People with experience in multi-culture workgroups know how difficult it used to be to get multicultural groups to function before the advent of information technology. People from different cultures tend to misunderstand each other's behaviours and hence come to distrust one another. It would be short-sighted to expect CSCW technology to overcome these problems. Indeed, Bots et al. in their position paper on the International Office of the Future (IOF) remark (pp. 11-12):

"We expect that within the IOF different cultures will be confronted with one another, creating new cultures. The evolution of cultures will result in changing demands towards the supporting technology. This will make it necessary to gain more in depth knowledge about the relation between organizational cultures and the impact on the possibility and use of supporting technology.

We can illustrate the differences in culture with respect to the inter-personal communication. The "distance" between manager and subordinate may widely differ from culture to culture. When people from different cultures get involved in direct communication, clashes may result. Good examples are the (internal!) consultant who is not expected to speak until he (or she!) is asked a direct question versus the consultant who is expected to take the lead, and the executive who can be approached only through a sequence of intermediaries. Imagine the consequences of these differences when implementing teleconferencing or even e-mail systems!"

This quotation makes it manifest that CSCW technologies cannot just be dumped into multiculture organizations, in particular multinational organizations. Research is needed on the interplay of technology and multicultural interaction. If possible the technology should facilitate the interaction, whereas in practice the opposite could occur. For instance, the executive in the quotation above might simply refuse to take part in electronic meetings, judging them to be below his dignity.

In the same text, the authors define an agenda for research. As one of the items in this agenda they mention (p. 13:) "a large-scale, international comparative study into the man-labor relationship". I believe that such a study already exists, and that its results can be of great value to address the problem of cooperation across cultures in the IOF. I am referring to the work of Geert Hofstede (Hofstede, 1980, recently described in a more accessible format in Hofstede, 1991). In the seventies, Geert Hofstede got access to data from a large-scale study on work-related values of IBM personnel in many countries. Since then, many have added to his work. His main findings, which have proved to be of value in both research and consultancy, are that the attitude of people towards their jobs and employers can be classified along a number of "dimensions of culture". These were found in a 
comparison among nationalities. They can be used to study cultural differences between individuals from different nationalities, but they have been found not to be suitable for comparing organizations. The reason for this is that organizations, unlike nationality, are partial in the sense that one is hardly ever a member of an organization to $100 \%$.

Hofstede's dimensions from the IBM study are: (a) power distance, as in the examples from Bots et al. above, (b) individualism versus collectivism, (c) masculinity versus femininity and (d) uncertainty avoidance. A fifth dimension was found with South-East Asian cultures: (e) long-term versus short-time orientation. The first three dimensions represent three fundamental relationships between people: vertical, horizontal, and gender-related. The latter two can be seen as the western and eastern version of a culture's orientation towards time.

Paul B. Pedersen and Allen Ivey (1993) used Hofstede's first four dimensions to create workshops through which they trained intercultural counselors. In these workshops, participants were divided into four groups. The groups then taught themselves a "synthetic culture", i.e. an extreme manifestation of one of Hofstede's dimensions. Then the four groups engaged in various interactions, depending on the context of the workshop.

What I have done is to adapt Pedersen and Ivey's workshops to problem situations that are likely to occur in the International Office of the Future. In the present workshop the participants have to design a communication architecture for an organization (Energy Forever inc.) that is setting up a global structure for sales and maintenance of windmills. Windmills cannot just be sold to customers in remote countries. Some initial training and some assistance in maintenance are necessary. Energy Forever have decided to put in place a proper communication architecture for the Windmill project.

The workshop serves two aims. First, it is a tool for research in intercultural communication in the context of CSCW, and second, it makes the participants aware of the pervasiveness of differences in culture, and hence motivates them to take these differences seriously in their work. As with any tool that is applied for the first time, both the tool and the results will come under scrutiny after the effort.

The paper goes on to describe the hypothetical case and the workshop first. Then, some background is given on CSCW technologies, which it is assumed the reader is reasonably familiar with, and on the "synthetic cultures" used in the workshop. Readers who are not familiar with dimensions of culture may wish to read the section on the synthetic cultures first before reading the rest of the paper. In the discussion which concludes the article, some preliminary results are presented of the three instances of the workshop held to date.

\section{THE CASE STUDY: ENERGY FOREVER, INC.}

Energy Forever inc. is a large, commercial provider of energy, based in Europe. With a yearly turnover of 3.500 million, bases in over 40 countries, an IS staff of some 500 people, and yearly expenditures on IT of some 10 Million, it is quite an enterprise, and ranks among the Global 100 remarkable IT users worldwide (as given in "Computerworld", June 1995). Energy Forever has been around for some thirty years, and most national branches have led a fairly stable life over the past few years, with typically some tens of employees, including field staff, per country. Its main products are electro-technical installations, ranging from simple gas-powered aggregates to complete power plants. Conventional sources of energy are Energy Forever's stronghold.

The research lab, having worked out the technology in experimental settings, has been advocating for some years that windmills should be added to FE's standard product range. A favourable political mood has now resulted in an advice by the Board and a subsequent decision by the CEO to launch a Windmill project: "the Windmills of Our Minds". The project's aim, apart from delivering 
sustainable energy at a favourable price, is to alter the company's image as a high-ranking polluter. This is worth a fair investment, so that the WOM project, as it is called, is not short of funds.

Having read Peter Keen's advice (Keen, 1991) that technical architecture and infrastructure should be seen by top corporate management as a long-range capital investment, the CEO wishes to position WOM as a model project in this regard. The project's first deliverable is to be a "communication architecture" for a global network for selling windmills of a variety of types (from modest and easy to maintain, but not very efficient, to extremely leading-edge) in a multitude of countries. The architecture must in particular support a sales and maintenance network for the windmills. Transferring knowledge from experience quickly across the sales and maintenance network is an important objective. As far as the choice of technologies goes, the project team has a free hand, and permission to "go grand".

In short, Energy Forever is a successful company, and the WOM project is a very innovative prestige project. Both the explicit concept of a "Communication Architecture" and the idea of adding windmills to the project range are very new. For the energy installations that Energy Forever currently sells there never has been a conscious design of a communication architecture for sales and maintenance.

Sales information at a company-wide level is only fed back to salespeople through the yearly business report which appears on paper and was also published on the company's WWW site this year. In some national branches there are additional flows of sales information, mostly through faceto-face meetings of personnel at company social events.

Maintenance information is currently not being gathered or kept centrally. There are files of repair jobs and of spare part orders in all national branches, though. From these files, some information about maintenance needs could be derived. Data on why an installation broke down is currently not collected, let alone spread in the organization.

There are some national differences in the way maintenance people are sent to maintenance jobs. Typically, they make fixed tours along a number of installations, and will interrupt these tours for emergency jobs. Most maintain radio contact with country headquarters. In some countries mobile phones have recently been introduced. Anecdotal information about repair jobs and their causes circulates widely and sometimes reaches the company's internal newsletter.

The workshop requires at least eight, but preferably twenty to thirty participants. It takes half a day, e.g. from 12.30 to 16.30 . The participants go through the following sequence of events (for each activity, sequence number, starting time in hours / minutes, title and contents are shown):

1. 12'30" Welcome. The participants fill in a questionnaire in which they give their views on culture-laden questions as well as on IT-related questions so that they will know more or less where they stand themselves with regard to Hofstede's five dimensions.

2. 13'00" Introduction. Using the questionnaire, the workshop leader introduces the synthetic cultures. The participants choose one of these as their own. During the rest of the workshop they will playact belonging to that culture.

3. 13'30" Warming up. All participants choose a group and do a few warming upexercises to acculturate. Then each synthetic culture group spends some time 
dividing roles: project leader, senior mechanic, junior executive, sales manager, computer specialist, secretary (optional), observant (optional). All read their role briefings.

4. 13'45" First project meeting. Each synthetic culture is given the same instructions about its task: to set up a communication architecture for windmill sales and maintenance. The main points of their proposal (including choice of hardware, CSCW software, data sets, organizational procedures, and roles of people), together with the main "dos and don'ts", are collected on flipover sheet or blackboard by the secretaries. Staying in one's role is more important than arriving at a sound proposal!

5. 14'00" Evaluation of the first project meeting.

6. 14'25" Consultant briefing. Each culture chooses one participant for a consultant. This person is assigned to the task of helping one of the other cultures out with their communication architecture. The group decides which objectives the consultant must absolutely attain with the other group.

7. 14'30" Coffee Break.

8. 15'00" Second project meeting. The consultants spend the meeting in the host group, then return to their own culture to report briefly. The consultants remain faithful to their own synthetic cultures. The secretaries adapt the flipovers if necessary.

9. 15'15" Evaluation of the second project meeting. This evaluation takes place within each culture group. The consultants remain in their original culture, and participants play their role.

10. 15'30" Plenary de-briefing. This is a plenary session to compare the various communication architectures and to discuss the confrontations between various cultures during the second project meeting. It includes a brief presentation of each group's communication architecture, as well as the consultants' account of how they fared in the host cultures.

11. 16'15" Workshop evaluation. This is a brief plenary reflection on the workshop as a whole.

12. 16'30" End of the workshop.

The communication architecture for the WOM project is supposed to be leading edge. It is therefore natural for the project team to look to CSCW technology.

For a choice of CSCW technologies, participants can draw on private knowledge and experience if they possess any. It is to be expected that the participants' level of a priori knowledge will vary rather widely. Well in advance of the workshop, participants who are in need of it will be given Roland Traunmüller's paper on CSCW in Bots et al. (1995).

Participants are free to choose conventional technologies such as paper mail, telephone, telefax or face to face contact. As for what is labelled CSCW, Traunmüller gives the following taxonomy (Bots et al. (eds), p. 33): 
Table 1 A taxonomy of CSCW technology, from Traunmüller (in Bots et al. (eds), 1995)

\begin{tabular}{|l|l|l|l|}
\cline { 2 - 4 } \multicolumn{1}{c|}{} & Same time & $\begin{array}{l}\text { Different time } \\
\text { (predictable) }\end{array}$ & $\begin{array}{l}\text { Different time } \\
\text { (not predictable) }\end{array}$ \\
\hline $\begin{array}{l}\text { Same place } \\
\text { (predictable) }\end{array}$ & meeting facilitation & work shifts & team rooms \\
\hline $\begin{array}{l}\text { Different place } \\
\text { (not predictable) }\end{array}$ & $\begin{array}{l}\text { whiteboarding, } \\
\text { desktop or video } \\
\text { conferencing }\end{array}$ & $\begin{array}{l}\text { electronic or voice } \\
\text { mail }\end{array}$ & collaborative writing \\
\hline
\end{tabular}

Any of these technologies could be applied.

A critical discussion of experiences with $\mathrm{CSCW}$ technologies or, as the author calls it, groupware, is given by Grudin (1994) in an issue on "social computing" of Communications of the ACM. Grudin identifies obstacles for success of groupware, some of which are obviously rooted in cultural factors. Table 2 below is taken from his paper. It can be used during the workshop's evaluation to discuss the five communication architectures.

Table 2 Eight challenges for groupware developers (from Grudin, 1994, p. 97)

1. Disparity in work and benefit.

Groupware applications often require additional work from individuals who do not perceive a direct benefit from the use of the application.

2. Critical mass and Prisoner's dilemma problems.

Groupware may not enlist the "critical mass" of users required to be useful, or can fail because it is never to any one individual's advantage to use it.

3. Disruption of social processes.

Groupware can lead to activity that violates social taboos, threatens existing political structures, or otherwise demotivates users crucial to its success.

4. Exception handling.

Groupware may not accommodate the wide range of exception handling and improvisation that characterizes much group activity.

5. Unobtrusive accessibility.

Features that support group processes are used relatively infrequently, requiring unobtrusive accessibility and integration with more heavily used features.

6. Difficulty of evaluation.

The almost insurmountable obstacles to meaningful, generalizable analysis and evaluation of groupware prevent us from learning from experience.

7. Failure of intuition.

Intuitions in product developments are especially poor for multiuser applications, resulting in bad management decisions and an error-prone design process.

8. The adoption process.

Groupware requires more careful implementation (introduction) in the workplace than product developers have confronted.

Incidentally, it also indicates how many obstacles exist to the introduction of groupware even in the industrialized countries, which seem to be the implicit setting of the article. The first and third obstacles from table 2 in particular are likely to be much higher still in a multi-cultural setting in 
which "non-industrialized" cultures participate. As for the sixth obstacle, difficulty of evaluation, it may be that workshops similar to the one proposed here can be of use in this area. Furthermore, an obvious, mundane obstacle to the adoption of groupware in developing countries is want of basic enabling technologies such as reliable telephone lines.

THE TEN SYNTHETIC CULTURES

The synthetic cultures are based on the work of Geert Hofstede $(1980,1991)$. Each of the five dimensions of national culture is a scale with two extremes. For each extreme of every dimension there is a synthetic culture, so that there are ten possible one-dimensional synthetic cultures in all.

Four of the synthetic cultures in the workshop are taken from Pedersen and Ivey (1993), who base themselves on Hofstede $(1980,1991)$. The remaining six are also taken from Hofstede (1991), but without the intermediary of Pedersen and Ivey. The fifth dimension, long-term orientation, did not figure in Hofstede's original data, because the original questionnaires, having been drawn up by a team without South-East Asian members, did not contain questions addressing this dimension. It was discovered later, using a questionnaire designed by South-East Asians. The particulars can be read in Hofstede (1991). Because this fifth dimension was found in a different setting from the first four, and because it has been less extensively researched, its appearance in this workshop is more tentative than that of the first four. All five dimensions are orthogonal, i.e. one's score on power distance has nothing to do with one's score on individualism, masculinity, uncertainty avoidance, or long-time orientation.

The workshop participants are given a presentation about the five dimensions before they make their choice. In some games, participants are not told the "culture bias" of other participants, but Pedersen and Ivey found that usually, telling the participants about all four synthetic cultures worked best in their workshops. Participants can then decide to choose either a synthetic culture that fits them, or one that is unfamiliar to them and about which they wish to learn more.

The Hipow culture is characterized by high power distance. Seven key elements of high power distance societies (selected from among many more, given by Hofstede (1991)) are:

1. Might makes right and power is good.

2. Power, status and privileges go together.

3. Less powerful people are dependent on more powerful.

4. Centralization is popular.

5. Subordinates expect direction.

6. The ideal boss is a benevolent autocrat or "good father".

7. Management theories focus on the appropriate roles of managers.

Some words that Hipows will use with a positive connotation are: respect, father (as a title), master, servant, older brother, younger brother, wisdom, favour, protect, obey, orders, pleasing.

Some words with a negative connotation among Hipows are: rights, complain, negotiate, fairness, task, necessity, codetermination, objectives, question, criticize.

The Lopow culture is the opposite of the hipow culture. It is characterized by extremely low power distance. Seven key elements:

1. Inequalities among people should be minimized. Privileges and status symbols are frowned upon.

2. There should be, and is, interdependence between less and more powerful people. 
3. Hierarchy in organizations means an inequality of roles only, established for convenience.

4. Decentralization is popular.

5. Subordinates expect to be consulted.

6. The ideal boss is a resourceful democrat.

7. Powerful people try to look less powerful than they are.

Words with a positive connotation among Lopows are those that hold a negative connotation among Hipows, and vice versa (see above for a list of such words).

The Indiv culture is highly individualistic. Seven key elements:

1. Honest persons speak their mind.

2. Low-context communication (abstract concepts) is preferred.

3. The task prevails over relationships.

4. Laws and rights are the same for all.

5. Trespassing leads to guilt and loss of self-respect.

6. Everyone has a private opinion on any topic.

7. The relationship between employer and employee is a contract based on mutual advantage.

Words with a positive connotation: self, friendship, do your own thing, contract, litigation, selfinterest, self-respect, self-actualizing, individual, dignity, I, me, pleasure, adventurous, guilt, privacy. Words with a negative connotation: harmony, face, we, obligation, sacrifice, family, tradition, decency, honour, duty, loyalty, shame.

The Collec culture is the opposite of the Inviv culture. It is extremely collectivist. Seven key elements:

1. Harmony should always be maintained and direct confrontations avoided.

2. Members of one's "in-group" (organization, extended family, ...) are sharply distinct from other, "out-group" people.

3. Relationships are more important than the task at hand.

4. Laws and rights differ by group.

5. Tresspassing leads to shame and loss of face for self and in-group.

6. Opinions are predetermined by group membership.

7. The relationship between employer and employee is perceived in moral terms, like a family link.

Words with a positive connotation are those that carry a negative one among Indivs, and vice versa.

The Mascu culture is highly masculine. Seven key elements:

1. Material success and progress are dominant values.

2. Bigger and faster are better.

3. Men are assertive, ambitious and "tough".

4. Women are tender and take care of relationships.

5. Failing is a disaster.

6. Conflicts are resolved by fighting them out.

7. Managers are expected to be decisive and assertive.

Words with a positive connotation: career, competition, fight, aggressive, assertive, success, winner, deserve, merit, balls, excel, force, big, hard, fast, quantity.

Words with a negative connotation: quality, caring, solidarity, modesty, compromise, help, love, grow, small, soft, slow, tender. 
The Femi culture is highly feminine. It is the opposite of the Mascu culture. Seven key elements:

1. Dominant values in society are caring for others and preservation (e.g. of the environment).

2. Small and slow are beautiful.

3. Everybody is supposed to be modest, men and women alike.

4. Conflicts are resolved by compromise and negotiation.

5. There is stress on equality, solidarity, and quality of work life.

6. Society is permissive.

7. Managers use intuition and strive for consensus.

Words with a positive or negative connotation are the same as for Mascus but with inverted sign.

The Uncavo culture is one of strong uncertainty avoidance. Seven key elements:

1. What is different is dangerous.

2. Familiar risks are accepted, but they fear ambiguous situations and unfamiliar risks.

3. There is an emotional need for rules, even if they will never work.

4. An appeal to existing rules is popular.

5. Time is money.

6. There is only one truth and we have it.

7. There is a belief in experts and specialization.

Words with a positive connotation: structure, duty, truth, law, order, certain, clean, clear, secure, safe, predictable, tight.

Words with a negative connotation: maybe, creative, conflict, tolerant, experiment, spontaneous, relativity, insight, unstructured, loose, flexible.

The Unctol culture is the opposite of the Uncavo culture. Uncertainty is extremely well tolerated by Unctols. Seven key elements:

1. What is different, is curious.

2. One is comfortable in ambiguous situations and with unfamiliar risks.

3. There should not be more rules than is strictly necessary.

4. Aggression and emotions should not be shown.

5. Being lazy feels good; one works hard when it is needed only.

6. There is tolerance of deviant and innovative ideas and behaviour.

7. There is a belief in generalists and in common sense.

Words with a positive or negative connotation are the same as for Uncavos but with inverse sign.

The Lotor culture is extremely long-term oriented. Key elements are:

1. Thrift is good.

2. Never give up, even if results are in want.

3. A sense of shame prevents one from doing what is wrong.

4. Traditions need not be immutable but can be adapted to a modern context.

5. Relations are ordered by status and this order is observed, but

6. There are limits to respect for social and status-related obligations.

7. Achieving one's purpose may be worth losing face.

Words with a positive connotation among Lotors: work, save, moderation, endurance, duty, goal, permanent, future, economy, virtue, invest, afford, effort.

Words with a negative connotation: relation, gift, today, yesterday, truth, quick, spend, receive, grand, tradition, show, image. 
The Shotor culture is the inverse of the Lotor culture. It is very short-time oriented. Seven key elements:

1. There is a social pressure to "Keep up with the Joneses", even if it means overspending.

2. Quick results are expected.

3. Never lose face.

4. Traditions should be respected.

5. Social demands (e.g. reciprocating gifts) are met regardless of cost.

6. There is a concern with possessing the Truth.

7. Saving is not popular, so that there is little money for investment.

Words with a positive or negative connotation are as for Lotors but with inverse sign.

\section{DISCUSSION}

\section{CSCW and dimensions of culture}

There is ample evidence that introducing technology in other settings than those in which it was invented can be deeply disruptive. In a book on management in developing countries, Kanungo and Jaeger set the scene with the following remark (Jaeger and Kanungo (eds) 1990), p. 1):

"Most widely dispersed management theories and techniques have their origin in the industrialized countries of the West. Many organizations in these industrialized countries have benefited from their prescriptions. As a result, western management thought and practice have turned into 'sacred cows' for industrial development."

However, it has been acknowledged for much longer that technology transfer across cultures causes the receiving culture to be under pressure. See, for instance, Goulet (1977), who uses a forceful argument as well as numerous case descriptions to make the point that technology from industrialized countries frequently upsets societies in non-industrialized countries if it is introduced there. Such non-industrial societies depend on shared significative values for stability. Stability, in turn, is needed because in non-industrialized societies resources are scarce and usually do not grow over time. Technology has historically taken away the need for stability, due to the manifold growth it entails. Simultaneously, technology enlarges markets, so that the circle of persons every member of society has to communicate with grows. So with the advent of technology, homogeneity in significative values is exchanged for shared normative values. You need to have some shared rules in order to do business, but you do not need to hold the same beliefs. Rather than a global village, we have a global marketplace.

The argument about the different roles of significative and normative values in developed versus developing countries is summed up by Goulet as follows (Goulet 1977, p. 21):

Whereas in less-developed societies a high level of integration exists between normative and significative values, economic activities are fragmented. A large number of production units - individuals, families, or villages - operate quite independently of others, and little coordination of effort or specialization of tasks is required. The opposite condition prevails in "developed" areas. There the basic symbols which explain history, life and personal destinies have no link to norms for action, but economic activity is so highly integrated that the autarchic subsistence of small units becomes practically impossible. Ultimately, the importance of the nexus between norms and meanings lies in this: In traditional societies work is a cosmic act; in developed societies, a specialized function."

One might object that the IOF is not about technology, but about communication and about the organization of work, so that it need not be disruptive. But the quotation above points out that in less-developed societies, communication and work themselves are subordinate to significative values, 
embodied in traditions. As a consequence, there is no way to change communication or the organization of work without upturning the significative value system.

In what way can we expect the International Office of the Future, and techniques advocated for use in the IOF, to affect value systems? Consider the visionary article by Roy Jacques in Bots et al (1995). On p. 23 he writes:

Point: "Workers have to stop doing simply what they are told, increase their job-relevant skills and invest more intelligence and emotional energy in their jobs". Point: "The employment relationship of the future is going to be more contingent; workers are going to have to think of their jobs as temporary. There is considerable tension between these two points".

This quotation, as the rest of Jacques" paper, has nothing to say on "significative values" as Goulet uses the word. It is about shifts that are required in work-related values. This means, perhaps, that to a western mind work-related values are significative values. They live in order to work, whereas in traditional societies one works in order to live.

Hofstede's dimensions of culture enable us to articulate just what value shift Jacques is predicting. According to him, a shift is required towards lower power distance, less uncertainty avoidance, and higher individualism. When we look at Hofstede's data, we see that these are the value combinations of Anglo-saxon countries, including the USA in particular. Other parts of the world have value systems that are much different: for instance, power distance is usually high, and individualism is low. So from their point of view, Jacques is foretelling that work in the IOF will require an even greater culture shift than if they had to adapt to current working conditions in industrialized countries.

Using historical data, centuries old in some cases, Hofstede (1991) also shows that value systems are very conservative. Consider once again the quotation from Bots et al. given in the introduction to this paper, which predicts that the IOF will create new cultures: there is a tension there too. So, to sum up, it becomes apparent that designing the multi-cultural IOF is definitely going to be a challenging process.

\section{The workshop as a tool for research}

It is very hard to predict the effects of office innovations without actually trying them out in practice. To quote Jacques once more (in Bots et al., 1995, p. 23):

"It is relatively easy to design an office with future-oriented work flows and technologies. It is relatively more difficult to understand how we will (collectively) create an environment in which workers exhibit the attitudes and behaviors on which these new work systems depend."

Because of the high risks and costs involved, workshops such as the one presented here can be, I believe, of value in directing research efforts in CSCW technologies and architectures that are appropriate for the International Office of the Future. The workshops, if well designed, can link a specific mix of cultures to a specific office design, and see the combination in action. Once an experience base of such "laboratory IOF's" exists, it can be helpful in two directions. If one knows that certain groups will have to cooperate, one can first gather knowledge about their cultural values and then design the office to fit. If, on the other hand, one has some known office design available, one can select personnel of which, given their value system, one can assume they will feel comfortable working within that design. This presumes that one can accurately obtain the candidates' cultural value systems (e.g. with help of Hofstede 1991, pp. 249 ff.).

The key assumptions here are that (a) one's work-related cultural values can be measured, and (b) office systems can be designed to fit workers' value systems. To put it mildly, these assumptions will most certainly not hold fully in all cases. But if only a small measure of improvement in the design of IOF's can be reached, the exercise will have been worthwhile. 
$\mathrm{CSCW}$ is but one of the many possible subject matters of a culture clash-workshop such as the one presented here. Incidentally, it proved to be quite ambitious to put both culture clash and IOFrelated content matter within one half-day workshop. If time permits, a stepwise approach is to be preferred, in which there is a first workshop in which the participants experience the synthetic cultures and the sense of culture clash, followed by a second one in which they attempt to deal with IOF-related subject matter while playacting different synthetic cultures.

The present workshop has a design task as its subject matter, which is itself not supported by advanced technology. Other types of tasks may not be sensitive to their performer's cultures in the same way. To find out about this, one can experiment in workshops with e.g. negotiation, document preparation, or coding tasks, under various conditions of support. This of course necessitates the availability of the supporting technology. At the multi-site IOF Conference planned for September 1997 (see Bots et al. 1995, p. vi) a multi-site culture clash workshop may be held.

\section{The workshop as a vehicle for creating awareness}

Pedersen and Ivey distinguish three phases in their work with counselors: awareness, knowledge and skill. First, the would-be intercultural counselors must be aware what differences in culture are, and what their own cultural values are. Then, they can gather knowledge of how meetings between participants from different cultures can go amiss, and what behaviours are appropriate when one communicates with somebody with a particular cultural background. Finally, they can practice skills in effectively communicating across cultures, adapting their behaviour as appropriate.

The workshop proposed here aims at opening the participants' eyes to the first level, that of awareness. This first step is probably the hardest one, and one which is much facilitated through actual experience of culture shock. Such an experience can be a true eye-opener to anyone, and particularly to one who has much schooling in the area of information technology, but little schooling in interpersonal communication and no experience of living in different societies.

Pedersen and Ivey's other phases, knowledge of the effect of differences in culture in workgroups on the design of CSCW technologies, as well as skills in using CSCW technologies in multi-culture groups, are concerns that will have to be addressed in the future. Laboratory situations may be put to good use here. For instance, one can use existing "real-world" technological infrastructures for experiments in which multi-cultural workgroups have to perform IOF-related tasks, as a first step in performing these tasks "for real". The experiments can be used for reflection, and for improving the architecture or the procedures associated with the architecture.

\section{EXPERIENCES WITH THE WORKSHOP}

The workshop has been held thrice: once in Wageningen in November 1995, once in Amsterdam in December 1995 (as an ICIS '95 pre-conference workshop of the "Cross-cultural research in IS" group) and once in Wageningen in January 1996. Some data on the three workshops are given in Table 3 below. 
Table 3 Overview of the three workshops "The Windmills of our Minds" given to date

\begin{tabular}{|l|l|l|l|}
\hline Workshop & $\begin{array}{l}\text { Number of } \\
\text { participants }\end{array}$ & $\begin{array}{l}\text { Number of } \\
\text { nationalities } \\
\text { represented }\end{array}$ & $\begin{array}{l}\text { Synthetic cultures } \\
\text { played }\end{array}$ \\
\hline Wageningen Nov'95 & 10 & 4 & Lopow, Mascu \\
\hline Amsterdam Dec '95 & 25 & 13 & $\begin{array}{l}\text { Hipow, Collec (2 } \\
\text { groups), Indiv }\end{array}$ \\
\hline Wageningen Jan'96 & 15 & 4 & Femi, Unctol, Lotor \\
\hline
\end{tabular}

Overall findings from these three repetitions can be summarized as follows.

a) The workshop fulfills its aim as a vehicle for awareness, according to statements made by the participants about how they experienced differences in culture. It is perceived as motivating and enjoyable. A great deal of enthusiasm and many intelligent comments were prompted by the workshop.

b) The workshop serves its aim of investigating the influence of culture on group design activities.

c) The workshop is far too short to allow for reflection. Hence its aim of serving as a tool for research is not realized to the full, simply because there is no time to link the workshop to the participants' real-world experience. A full day would be required at a minimum to allow for discussion about the workshop, and one more day to link the workshop to everyday experience. Despite the lack of time in the current formula, the idea of using conditioned experiments to investigate office environments is definitely reinforced by the workshop.

d) Enacting a synthetic culture truthfully is quite hard to do. Time for reflection about acting performance, and about whether what happened during the meetings was faithful to the synthetic culture being enacted, would be an improvement. Also, having to enact both an individual role and a culture role while at the same time having to perform a design task is really hard to do for many participants. Two remedies apply: first, the personal role briefings can be dropped, and second, the workshop should only be given to people with a background in the content matter of the case study. Having two meetings, so that the first can serve as a starter for the second, proved to be a good idea.

Table 4 gives an impression of how the various culture groups fared with regard to the process and to the result of their first meeting. No claim is being made other than to describe what happened. Repetitions of the playing of identical encounters with different fictive cultures will no doubt show that personal and interpersonal factors play a role which may alter the balance of a meeting completely. I also suspect that players from Europe or the Anglo-saxon countries tend to add femininity when they enact collectivity, and to add low power distance when they enact femininity. 
Table 4 Summary of the first meetings

\begin{tabular}{||l|l|l||}
\hline Synthetic culture (date) & Process & Result \\
\hline Hipow (Dec. '95) & hostile, subdued & centralized \\
\hline Lopow (Nov. '95) & $\begin{array}{l}\text { time-consuming, nobody } \\
\text { decides }\end{array}$ & egalitarian, internal orientation \\
\hline Collec (Dec. '95, 2x) & family & various \\
\hline Indiv (Dec. '95) & noisy. coalitions \& fights. & buck passing \\
\hline Femi (Jan. '96) & warm, outgoing & $\begin{array}{l}\text { egalitarian, internal orientation, } \\
\text { education }\end{array}$ \\
\hline Mascu (Nov. '95) & quick, efficient & external orientation, competitive \\
\hline Uncavo & - & - \\
\hline Unctol (Jan. '96) & culture not dominant & enabling communication \\
\hline Shotor & - & - \\
\hline Lotor (Jan. '96) & disciplined & strategic \\
\hline \hline
\end{tabular}

As far as the second meeting is concerned the situation is more complex: 200 combinations of consultant and host culture are possible. One can speculate about what values are in general desirable for a consultant. Femi, Indiv and Unctol are candidates. As far as the host culture is concerned, the experiences so far make me suspect that a Hipow or Collec host culture can induce strong culture shock in most consultants.

In order to obtain results that can be used in practice, it will be useful to experiment with host/consultant culture combinations that one expects to occur in actual practice, and to compare the findings with field data. Also, as stated before, extended time for discussion, e.g. watching video images of the workshop meetings, and including real-world experiences that participants have had with multi-cultural meetings, will help separate incidental results from results that are rooted in culture differences.

The workshop described here will, I hope, be the first in a family. There still are some data to process, i.e. the culture questionnaires filled in by the participants. Also, a number of comments are still awaiting further reflection. Finally, a number of initiatives are under way to extend the formula to other settings: for use in virtual task environments, during courses and trainings, with different subject matter, and with different conditions of conditioning.

\section{ACKNOWLEDGEMENTS}

Thanks go to Pieter Bots, who encouraged me to pursue the idea which led to this workshop. I am indebted to Geert Hofstede and Paul Pedersen for the comments they made about an earlier version of the paper. I wish to thank Marlies Tjallingii for her advice which helped me improve the workshop's schedule. Thanks are also due to four anonymous reviewers, whose recommendations I have followed as far as time permitted. Finally I am grateful to the participants for "making it 
happen" on three occasions. Some of them will find I acted upon their suggestions to improve the workshop.

\section{REFERENCES}

Bots, Pieter W.G. et al. (eds) (1995) The International Office of the future: A Problem Analysis. Technical University, Dept. Of Systems Engineering, Delft.

Goulet, Denis (1977) The Uncertain Promise: Value Conflicts in Technology transfer. IDOC/North America, New York.

Grudin, Jonathan (1994) Groupware and Social Dynamics: Eight Challenges for Developers. In Communications of the ACM, 37:1, Jan 1994, pp 92-105.

Hofstede, Geert (1980) Culture's Consequences: International Differences in Work-related Values. Sage Publications, Beverly Hills, CA.

Hofstede, Geert (1991) Cultures and Organizations, Software of the Mind: Intercultural Cooperation and its Importance for Survival. McGraw-Hill, London.

Jaeger, Alfred M. And Rabindra N. Kanungo (eds) (1990) Management in Developing Countries. Routledge, London.

Keen, Peter G. (1991) Shaping the Future: Business Design through Information Technology. Harvard Press, Boston, MA.

Pedersen, Paul B. and Allen Ivey (1993) Culture-centered Counseling and Interviewing Skills. Praeger, Westport.

\section{BIOGRAPHY}

Gert Jan Hofstede, a biologist by vocation, has worked as an information systems professional since 1984. He wrote a Ph.D. dissertation, titled "Modesty in Modelling", about the applicability of formal models in decision support systems. He teaches data modelling. His research interests include Soft Systems methodology and the influence of cultural factors on designated tasks carried out by groups. 